\title{
Serenidad de Deleuze: la escritura como engranaje de montaje
}

\section{Deleuze's Serenity: writing as Gear of Montage}

\section{Román Domínguez Jiménez}

Instituto de Estética, Facultad de Filosofía, Pontificia Universidad Católica de Chile, Santiago, Chile

\section{Resumen}

Este artículo indaga la eventualidad de una escritura del Siglo XXI fiel a lo propuesto por Deleuze en su texto sobre Nietzsche intitulado Pensamiento nómada: una escritura que, de un modo más cinematográfico que propiamente escritural, lograría conectar el texto con el afuera (las cosas, el Cosmos). Esto implicaría una aproximación estético-política que enfatizaría más la sensibilidad que la filosofía política tradicional, cuyo énfasis recae en la construcción de legitimaciones y de dinámicas meta-estables como es el juego de la democracia representativa. Esta eventualidad se abre con el análisis de ciertas particularidades de la lectura que François Zourabichvili hace de los textos de Deleuze, y de Deleuze y Guattari. En contra de esta lectura (a la que al proponer la literalidad en la sintaxis como modo operatorio principal de los textos de estos autores, el autor de este $p a-$ per le adjudica el logro involuntario de haber descubierto un peligro efectivo de locura y de suicidio en Deleuze y Guattari), se propone, a partir de lo dicho por el propio Deleuze 
en Pensamiento nómada, una lectura técnica que considera al texto y la sintaxis como elementos de un montaje extratextual. Lo que se lograría, sería conjurar la eventualidad de una locura (filosófica y/o real) derivada de la asimilación literal de la escritura con la vida, sin dejar por ello de enfrentarse al riesgo que implican las escrituras que, como las de Deleuze, implican un vértigo filosófico y estético por su manera de relacionarse con el mundo para crear nuevas situaciones.

Palabras clave: Deleuze. Zourabichvili. Montaje. Literalidad. Locura.

\section{Abstract}

This article inquires into the eventuality of a 21st-century writing [écriture] faithful to what Deleuze proposes in his text on Nietzsche, which is entitled Nomad Thought: a writing that, in a manner that will be more cinematographic rather than purely scriptural, would achieve a connection between the text and the outside (things, the Cosmos). This approach implies an aesthetic-political stance that places a greater stress on sensibility than traditional political philosophy, since the latter's emphasis lies commonly in the construction of legitimations and meta-stable dynamics such as the game of representative democracy. This eventuality opens up in light of analysis of certain particularities in François Zourabichvili's reading of texts by Deleuze, and Deleuze and Guattari. Against this reading (to which, by proposing literality in syntax as an the main operational mode of these authors' texts, the author of this paper adjudicates the involuntary discovery of an actual danger of madness and suicide in Deleuze and Guattari), and following what is said by Deleuze himself in Nomad Thought, a technical reading that considers text and syntax as elements of an extra-textual montage is presented. This approach would conjure the eventuality of a (philosophical or actual) madness derived from literal assimilation of writing with life, without avoiding the risk that writings such as Deleuze's pose by implying a philosophical and aesthetic vertigo because of their way of relating to the world in order to create new settings.

Keywords: Deleuze. Zourabichvili. Montage. Litéralité. Madness. 


\section{Preámbulo (a manera de introducción)}

Es sabido que tanto para Deleuze, como para Deleuze y Guattari - este autor doble que no puede ser reducido a la firma de Deleuze, del mismo modo que Bustos Domecq no es ni Borges ni Bioy Casares la textura del campo político tiene un carácter muy singular. Para estos autores no se trata en absoluto de hacer filosofía política, como puede ser la de Hobbes, la de Marx y sus seguidores; o la de Leo Strauss, la de Carl Schmitt o aun las de Claude Lefort, Chantal Mouffe o Ernesto Laclau. Al contrario: se trata de una suerte de llamado de atención, un clamor contra la repartición y el despliegue de lo político y del poder que ha llevado a cabo la filosofía política. Lo que ésta suele repartir son modelos, roles, conductas y contra-conductas detectables y asignables a un plano dado, el nomos. Mientras que lo que Deleuze, y Deleuze y Guattari, buscan son cortocircuitos, desniveles y fugas que sólo pueden remitirse a efectos y estrategias que desvirtúan lo dado, el poder, para constituir un plano tambaleante, como quebrado por grietas, una dinámica excéntrica. Lo que se instauraría así no sería la ley, ni una simple contra-conducta, sino la sensibilidad como falsa ley, la deriva de una fisura perversa que destituye al nomos.

Lo anterior explicaría porque por ejemplo para Deleuze (1993 1), la estrategia de declinación (I would prefer not to...) en Bartleby ou la formule [Bartleby o la fórmula] ${ }^{1}$ es más importante que cualquier definición de democracia y soberanía: "aun catatónico y anoréxico, Bartleby no es el enfermo, sino el médico de una América [Estados Unidos] enferma,

1 En la primera referencia, citamos cada texto de Deleuze, en solitario o con Guattari, con su título original en francés en itálicas, seguido de su traducción al castellano entre corchetes. Las citas textuales de estos mismos autores son en todos los casos traducciones nuestras al castellano, que por lo mismo pueden variar ligeramente de las traducciones canónicas. En los casos en que la argumentación lo requiere, citamos el texto original en francés entre corchetes. Para dar una mejor cuenta de la cronología de los textos, y si no han sufrido modificaciones considerables, los referenciamos tanto en el cuerpo como en la lista de referencias con su año de publicación original más que con el año de su publicación como texto de antología o capítulo de libro. Si el capítulo de libro puede considerarse más como un texto aparte, lo señalamos tanto en el cuerpo del trabajo como en las referencias finales como un texto autónomo, como es el caso de Bartleby, ou la formule, que referenciamos como (Deleuze 1993 1). № así en el caso de textos que aunque tengan una argumentación relativamente independiente, pueden considerarse como parte de una argumentación más amplia, como es el caso que veremos más adelante del apartado Máquina de guerra de Mil Mesetas. 
el Medecine-Man [sic], el nuevo Cristo o el hermano de todos nosotros" (p. 114). También aquí estaría la razón de porqué en Mille Plateaux [Mil Mesetas] de Deleuze y Guattari (1980), el hilo genealógico del concepto político de Máquina de guerra, no fue confeccionado con textos de pensadores estrictamente políticos, sino con fragmentos de los filólogos Dumézil, Detienne y Vernant; con referencias a las etnografías preparadas por los antropólogos Clastres, Meunier, Jules Bloch, y Luc de Heusch; con reenvíos a los análisis literarios de Starobinski; con comentarios al estudio de Michel Serres sobre Lucrecio y a las nociones de espacio del músico Boulez y del urbanista Virilio; a las obras de los matématicos Monge, Poncelet, Desargues y Lautman; a la fenomenología de Husserl; a los estudios sobre la técnica de Leroi-Gourhan y Simondon; a la Muqaddima de Ibn Jaldún; al libro de Wörringer sobre el arte gótico; a los estudios sobre la metalurgia de Henri Limet, Maurice Lombard, R. J. Forbes y Walter Cline; al Timeo de Platón; a los textos de Castañeda y Kenneth White; a Seven Pilars of Wisdom de T. E. Lawrence, a un improbable estudio de Aly Mazaheri publicado en Annales en 1958 sobre el sable y la espada. Aun la inclusión de Clausewitz tendría que ver más con una estrategia de la sensibilidad que con la confección de la filosofía política. Es así que en este apartado "1227 - Tratado de nomadología: la máquina de guerra” (DELEUZE y GUATTARI, 1980, p. 434-527), la estructura de los polos en que reposa el aparato de Estado (las deidades de Mitra y Varuna; rey mago y sacerdote jurista; lo violento y lo tranquilo; lo rápido y lo grave; la ligazón y el pacto), así como la exterioridad de la Máquina de Guerra respecto a dicho aparato (el dios Indra, lo múltiple, lo inconmensurable, lo efímero, lo proteíco), provienen esencialmente de un oscuro libro sobre mitología indoeuropea de Dumézil: Mitra-Varuna. Essai sur deux représentations indo-européennes de la souveraineté (1940).

Hay una línea oscura y quebrada que liga el desdén de Deleuze a la filosofía política clásica con la Hacia la crítica de la violencia de Benjamin (2007), quien traza la división entre violencia mítica y violencia liberadora a partir de la diferencia entre la mitología griega y el Dios de los hebreos; y más recientemente con El Reino y la Gloria de Agamben (2008), quien demuestra, siguiendo a Schmitt y al historiador 
Kantorowicz, pero también al antropólogo Mauss y al cabalista Mopsik entre otros, que la soberanía y el gobierno tienen su origen en la oikonomia de la teología occidental. Se puede afirmar que tanto en el caso de la declinación de Bartleby de Deleuze, como en la confección de la Máquina de guerra de Deleuze y Guattari, lo político no es tanto la legitimación de un Estado o la instauración de un estado de cosas permanente o aun de una dinámica política metaestable (el juego de la democracia), sino de destituir, de tergiversar, de pervertir, de renunciar a lo que hasta ahora ha sido la política.

Pero sería reductor entender que este clamor tenaz de Deleuze y de Deleuze y Guattari a favor de lo sensible y en contra de la filosofía política es un llamado a favor de una política del arte o de la mera literatura. No sin humor nietzscheano, Deleuze y Guattari postularán en Mil Mesetas que "El Arte [con mayúscula] es un falso concepto, únicamente nominal" (DELEUZE Y GUATTARI, 1980, p. 369); y que el arte es ante todo labor de animales y de pájaros: hacer afiche, pancarta (p. 389). Más tarde, en Qu'est-ce que la philosophie? [¿Qué es la filosofía?] (1991) Deleuze y Guattari retomarán la frase de Le Clézio en Haï (1971, 8): “Un día, se sabrá quizá que no había arte, sino solamente medicina" [Un jour, on saura peut-être qu'il n'y avait pas d'art, mais seulement de la médecine] (DELEUZE Y GUATTARI, 1980, p. 163). Esto no implica una objeción al interés que estos autores muestran en sus obras por el arte, y al lugar preponderante que le otorgan justamente en ¿Qué es la filosofía?: como una forma de pensamiento y experimentación que interactúa y que interfiere con la ciencia y la filosofía. Lo que para ellos ha sido siempre un falso problema es la lectura antropológica que hace del arte un dominio espiritual autónomo y superior. El arte fue para Deleuze y para Deleuze y Guattari, la pedagogía de la otra política. Es un lugar común afirmarlo, pero lo que interesó a estos autores son los devenires, las desterritorializaciones, la experimentación: en el arte, pero también en la política o, para decirlo a la manera del propio Deleuze, la experimentación en la zona en la que la sensibilidad (el deseo, lo estético) y la política (la fuga, la invención de nuevas configuraciones) son una sola cosa. Zona, territorio o ámbito de vértigo que por lo pronto podríamos llamarla, más allá del arte y la filosofía política, la franja 
estético-política. El propósito de este texto es apuntar como se desarrolla por parte de Deleuze, y de Deleuze y Guattari (entendidos como dos autores distintos que se entrecruzan), dicha franja en la escritura, y como ésta se desarrolla más allá de lo que el especialista en Deleuze François Zourabichvili (2007) denomina literalidad.

\section{Montaje y escritura}

Foucault (1970) apuntó en Theatrum philosophicum: que "algún día, quizá, el siglo será deleuziano" [Mais un jour, peut-être, le siècle sera deleuzien] (p. 885). A pesar de este vaticinio habría pocos motivos para creer que este siglo XXI, es deleuziano o deviene deleuziano. Habrá quien refute y diga que efectivamente sí vivimos en un mundo en el que el carácter rizomático de las relaciones y de la comunicación en las nuevas tecnologías y el delirio del Capital en el Siglo XXI le da la razón a Foucault respecto a Deleuze y a Deleuze y Guattari. Pero ello no basta para declarar deleuziano al siglo: hemos entrado en una deriva de civilización en la que las fuerzas dominantes son las pasiones tristes, las fuerzas reactivas y reaccionarias que promueven - entre los universitarios y empresarios por ejemplo - un nomadismo cuya sola aventura es la elección de un asiento de clase económica. Habría que complementar nomadismo in situ vindicado por Deleuze y Guattari (1980, p. 602), con el nomadismo vano prefigurado por Borges (1945): "Viajar, ahora, es una de las formas más costosas de la inmovilidad" (p. 166). Se trata en suma de fuerzas que no cesan de ahogar todas las posibles líneas de fuga, de poderes que no cesan de vendernos la idea de que no podemos hacer nada más, de que estamos condenados a las protestas pírricas en la red y en la calle, que lo sensible y la percepción están después de la ley, que el nomos determina implacablemente la vida misma. A pesar de vivir una época de constante aceleración, como lo constatan desde hace tiempo los textos de Virilio y de Harmut Rosa, no tenemos más una teoría como la de Deleuze que pueda afrontar el caos, que pueda hacer del vértigo una facultad superior ¿Cómo enfrentar esta situación? ¿Dónde encontrar a los deleuzianos, a los 
nómadas de hoy día? Una pregunta análoga se hizo Deleuze respecto a Nietzsche en su texto Pensée nómade [Pensamiento nómada] (1973): “¿Quién es el joven nietzscheano de hoy?” [qui est-ce aujourd'hui, le jeune homme nietzschéen ?]. Para plantear esta cuestión Deleuze caracterizó la escritura de Nietzsche como descodificadora, en oposición a las escrituras codificadoras o recodificadoras de Marx y de Freud. Si en Marx y en Freud, Deleuze encontró relaciones que legalizan, que reglamentan, contratan, que institucionalizan ${ }^{2}$, en Nietzsche, principalmente en el aforismo, Deleuze descubrió el advenimiento de otra relación: "estar embarcado con" [être embarqué avec] (p. 355), un movimiento de deriva, de desterritorialización. El carácter definitivo de la escritura y del pensamiento de Nietzsche según Deleuze es su relación con el afuera. Se trata de textos que para Deleuze no significaban nada antes de su conexión con un movimiento que es exterior a ellos. Como apuntó Deleuze:

[...] un aforismo es un juego de fuerzas, un estado de fuerzas unas siempre exteriores a las otras. Un aforismo no quiere decir nada, no significa nada, y no tiene más significante que significado. Que serían maneras de restaurar la interioridad de un texto. Un aforismo es un estado de fuerzas, del cual la última, que es también la más reciente, es siempre la más exterior. Nietzsche lo propone muy claramente: si se quiere saber lo que quiero decir, encuéntrese la fuerza que da un sentido, o un nuevo sentido, a lo que digo. Conéctese el texto a esta fuerza. De esta manera no hay problema de interpretación de Nietzsche, no hay sino problemas de maquinación: maquinar el texto de Nietzsche, buscar con que fuerza exterior hace pasar algo, una corriente de energía. [Un aphorisme, c'est un jeu de forces, un état de forces toujours extérieures les unes aux autres. Un aphorisme ne veut rien dire, ne signifie rien, et n'a pas plus de signifiant que de signifié. Ce seraient des manières de restaurer l'intériorité d'un texte. Un aphorisme est un état de forces, dont la dernière, c'est-à-dire à la fois la plus récente, la plus actuelle et la provisoire-ultime est toujours la plus extérieure. Nietzsche le pose très clairement: si vous voulez savoir ce que je veux dire, trouvez la force qui donne un sens, au besoin un nouveau sens, à ce que je dis. Branchez le texte sur

2 Deleuze no fue por ello contrario a pensar los modos afirmativos, a la vez que perversos, del contrato y de la Ley, como muestra su texto Présentation de Sacher-Masoch [Presentación de Sacher-Masoch] (1967). 
cette force. De cette manière il n'y a pas de problème d'interprétation de Nietzsche, il n'y a que des problèmes de machination : machiner le texte de Nietzsche, chercher avec quelle force extérieure actuelle il fait passer quelque chose, un courant d'énergie] (p. 357).

Podría conjeturarse que la manera que Deleuze tuvo para entender, para asumir, para experimentar los textos de Nietzsche implicó una propuesta de lectura ontológica que intentó romper con la interioridad de Occidente, o bien una lectura hermenéutica que buscó conectarse con la lejanía en tanto que índice de alteridad. Pero como más adelante se tratará de justificar, pudo haberse tratado de una postura o de una propuesta de lectura de carácter técnico: es decir, una propuesta que economiza la escritura hasta considerarla como una mera interfaz en el seno un ensamblaje estético-político mayor, no-literario, no-lingüístico, incluso no-escritural. Es el exterior innombrado lo que siempre otorga su sentido al texto en una escritura descodificadora. Hasta aquí no se ha dicho nada nuevo: es conocido el gusto de Deleuze y de Deleuze y Guattari por entender, por experimentar, por asumir un texto como algo maquínico, como una pieza de ensamblaje que se conecta con el deseo y con lo real. Lo que es específico en el caso de la lectura del aforismo y de la escritura de Nietzsche por Deleuze es su modo de conexión: se trata de una concepción casi cinematográfica del texto. Por ello no es casual la comparación que Deleuze hace del aforismo nietzscheano con el modo operatorio de los filmes de Godard: el aforismo es como un cuadro o plano que se ve afectado por una fuerza que viene desde afuera y lo atraviesa: "como en el filme de Godard: se pinta el cuadro con el muro. Lejos de ser la delimitación de una superficie pictórica, el cuadro [el plano] es casi lo contrario, es la puesta en relación inmediata con el afuera" (p. 356). El modo operatorio de los textos de Nietzsche según Deleuze es eminentemente cinematográfico. Un aforismo es como un plano; su afuera es el fuera de campo. Se puede incluso afirmar que para Deleuze escritura de Nietzsche y el cine funcionan de manera similar, como piezas de un montaje cinematográfico, pues lo mismo que dice de Nietzsche puede ser adjudicado al cine de Godard o al de Farocki: 
su fuerza no está en el plano, sino en su potencialidad para conectarse con un fuera de campo, para crear relaciones que no son visibles pero que pasan por lo visible, como un rayo que testimonia la fuerza del cielo o una estrella fugaz la fuerza del cosmos.

\section{La conexión con el afuera}

Ahora bien, quizá la clave no sólo para entender este texto de Deleuze, sino la relación que Deleuze mantiene con la escritura se encuentra en la respuesta a la pregunta que le hace André Flécheux a Deleuze en su exposición y que se encuentra al final del texto Pensée nomade. Flécheux reprocha a Deleuze el hacer economía de la deconstrucción derridiana - el famoso il n'y pas de hors-texte (DERRIDA, 1967, p. 220) - y de presentar así una lectura naïve de Nietzsche y del nomadismo. A lo que Deleuze responde:

Respecto al método de deconstrucción de textos, sé muy bien lo que es, lo admiro mucho pero no tiene nada que ver con el mío. No me presento de ninguna manera como un comentador de textos. Un texto, para $\mathrm{mi}$, no es sino un pequeño engranaje en una práctica extratextual. No se trata de comentar un texto por un método de deconstrucción o por un método de práctica textual o por otros métodos, se trata de ver para que sirve este en una práctica extratextual que prolonga el texto. [Quant à la méthode de déconstruction des textes, je vois bien ce qu'elle est, je l'admire beaucoup, mais elle n'a rien à voir avec la mienne. Je ne me présente en rien comme un commentateur de textes. Un texte, pour moi, n'est qu'un petit rouage dans une pratique extratextuelle. Il ne s agit pas de commenter le texte par une méthode de déconstruction, ou par une méthode de pratique textuelle, ou par d'autres méthodes, il s'agit de voir à quoi cela sert dans la pratique extratextuelle qui prolonge le texte] (DELEUZE, 1973, p. 363).

En este pasaje asistimos a un acto de parresia, de franc-parler de Deleuze: "no me presento como un comentador de textos". De lo anterior se deriva que pocos pueden decir en filosofía y en otras partes que son o que están deviniendo deleuzianos. Y es que la época teórica 
no parece prestarse - mucho menos en el contexto universitario - al uso que propone Deleuze de la escritura. Aquí nos percatamos que el asunto ya no es Nietzsche sino la propia práctica deleuziana del texto y del pensamiento. Quizá la extratextualidad de Deleuze se define en el arte de comenzar y de concluir un texto. Uno de los atributos principales sus textos es su manera de comenzar y de finalizar. Hay algo de ritual de samurái en los textos de Deleuze. Siempre comienzan con un movimiento que se enfrenta con el afuera desde la primera acometida, como el samurái que ve venir el peligro y desenvaina, no siempre para atacar de frente, sino para literalmente conectar la espada con la fuerza exterior y dar un sentido distinto a ambos movimientos: el que viene de afuera, el que acomete el samurái. De cierta manera es este primer movimiento el que define la suerte de un texto y de la práctica extratextual. El principio y el final son los bordes del texto, son estos los que van a permitir unirlo con su afuera con más o menos fuerza, con su fuera de campo. Lo que no implica que la conexión con el afuera se reduzca a estos momentos, sino que principio y final son como las costuras de un texto que va a funcionar como una membrana o textura que comunica la escritura con su afuera. Son célebres los inicios de L'AntiCEdipe [El Anti-Edipo] (DELEUZE Y GUATTARI, 1973) y del Nietzsche et la philosophie [Nietzsche y la filosofía] (DELEUZE, 1962). Pero vale la pena recordar éste, de Le pli [El pliegue] (DELEUZE, 1987):

El Barroco no remite a una esencia, sino más bien a una función operativa, a un trazo. No cesa de hacer pliegues. No inventa la cosa: hay todos los pliegues que vienen de Oriente, los pliegues griegos, romanos, románicos, clásicos ... Pero él curva y recurva los pliegues, los lleva al infinito, pliegue sobre pliegue, pliegue de acuerdo al pliegue. El trazo del Barroco es el pliegue que va al infinito (p. 5).

Y este otro, de Presentación de Sacher-Masoch (1967), del que apuntamos sólo un fragmento :

¿Para que sirve la literatura? Los nombres de Sade y Masoch sirven por lo menos para designar dos perversiones básicas. Son los ejemplos prodigiosos de una eficacia literaria. ¿En qué sentido? (p. 15). 
Y hacia el final de los textos de Deleuze, siempre hay un momento a la vez desbordante y tierno, decisivo y abierto, de una rara solemnidad, como cuando el samurái envaina de nuevo su espada. Al ya citado final de Bartleby y la fórmula, hay que agregar este, sencillo, de la parte de "El ritornelo" de Mil Mesetas: "Solamente que jamás se está seguro de ser suficientemente fuerte, porque no hay sistema, no hay sino líneas y movimientos. Schumann". (DELEUZE Y GUATTARI, 1980, p. 433). La conexión con el afuera puede darse también en frases que son como los haikus de Deleuze. Como en ésta, fulminante, de L'Image-Temps [La Imagen-tiempo] en la que vindica a Pasolini frente a los ataques de Umberto Eco, pero que como los aforismos de Nietzsche, o aun los de Gracián, puede ser conectada con una fuerza exterior actual: "Es destino de la astucia, parecer demasiado ingenua a ingenuos demasiado sabios" [C'est destin de la ruse, de paraître trop naïve, a des naïs trop savants] (DELEUZE, 1985, p. 42).

\section{Escritura y locura}

¿Pero como experimentar, expresar y crear una escritura, o si se quiere, una textura deleuziana, hoy día? En el entendido que una textura es una superficie que es algo menos y quizá algo más que un texto. No se trata de ir en contra del texto o la escritura, sino de encontrar las fisuras en el mundo presente que nos permitan pensar el texto como un engranaje o interfaz, o como un plano que se conecta con el fuera de campo para crear sentido, para establecer nuevas conexiones de pensamiento que no se queden en la repetición de la voz del maestro. No se puede anunciar quienes serían los deleuzianos de hoy sin una cierta falta de pudor, pero lo que si se puede sugerir e invocar es la eventualidad de una práctica textual y extratextual que bien pudiera convenir a un deleuzianismo de hoy. Ello implica cernir el riesgo que debe afrontar lo que podría ser un texto neo-deleuziano hoy día. Este riesgo se da menos en la confrontación con los enemigos metafísicos de Deleuze (el poder, las pasiones tristes, el nomos, el platonismo, el fascismo) que en el peligro de la propia escritura, en el vértigo que causaría 
una escritura deleuziana de nuestro tiempo. No hay vértigo sin propensión a la locura y sin peligro mortal. Y la escritura de Deleuze pasa siempre por el vértigo: se trata de afrontar la locura y la muerte en la franja estético-política para extraer de ella nuevas sensibilidades y nuevas formas de vida; para decantar de esta confrontación una victoria de lo minoritario, de lo casi imperceptible, de lo inhumano, del devenir.

Acaso fue este el peligro del que no salió indemne François Zourabichvili, quien se suicidó en 2006, en el apogeo de su fama como lector de Deleuze y como filósofo por derecho propio. Resulta que al contario del suicidio de su maestro (Deleuze, enfermo de cáncer se suicida a los 70 años tirándose desde una ventana, Zourabichvili se suicida a los 40 años con la misma operación), Zourabichvili se encontraba en la plenitud de la edad ¿pudo haberse tratado de un suicidio filosófico, más que de un problema existencial? Tal situación no puede resolverse positivamente con una estricta separación entre obra filosófica y vida, como tampoco en una amalgama fácil de ambas, sino acaso en una conjetura sobre la locura en la escritura de Deleuze. Lo que no equivale a afirmar que Deleuze haya estado loco o que sus textos sean el art brut de un desequilibrado, sino a pensar que acaso su escritura está traspasada por la locura de la misma manera en que Deleuze mismo intuye que en la obra de Proust, la locura está muy presente (DELEUZE, 1975, p. 30). Esta presencia de la locura implicaría para el lector la pretensión de ganar algo con ella, o de salir victorioso al atravesarla, pero también ciertamente el peligro de perderse.

¿Habría luego una locura propia a la escritura de Deleuze, a la manera en que Derrida la encuentra en Kant? En uno de sus últimos seminarios en la École d'Hautes Études en Sciences Sociales, Derrida (2015) sugirió que habría una locura propia a la razón kantiana "folie de la raison kantienne" (p. 248-249, nota 1) que habría que deconstruir. Ya que Kant considera que la pena capital es altamente moral porque cumple con el imperativo categórico: la pena no se ejecuta por ejemplaridad o utilidad pública, sino porque es un acto que da significación moral al crimen y confiere al condenado la dignidad de hacerlo sujeto de la ley. En efecto, Kant (2008) señala que 
Aun cuando se disolviera la sociedad civil con el consentimiento de todos sus miembros (por ejemplo, decidiera disgregarse y diseminarse por todo el mundo el pueblo que vive en una isla), antes tendrá que ser ejecutado hasta el último asesino que se encuentre en la cárcel, para que cada cual reciba lo que merece sus actos y el homicidio no recaiga sobre el pueblo que no ha exigido este castigo: porque puede considerársele como cómplice de esta violación pública de la justicia (p. 168-169)

Derrida no rechaza inmediatamente el argumento kantiano a favor de la pena de muerte, busca algo más complicado: revelar su no-impermeabilidad (non-étanchéité) (p. 291), es decir, su pretendida distinción entre lo justo y la violación de lo justo. En Deleuze, y en Deleuze y Guattari, la locura no sería la ambigua apología de la esquizofrenia en el Anti-Edipo o la perversión del contrato en Presentación de Sacher-Masoch, sino un punto que justamente Zourabichvili trató de precisar: la cuestión de la literalidad en los textos Deleuze. En efecto, en La question de la littéralité, Zourabichvili (2007) ${ }^{3}$ recuerda muy bien como Deleuze, y Deleuze y Guattari - aunque Zourabichvili no precisa tanto la diferencia entre estos dos autores - , insisten en varios pasajes de sus obras en no tomar ni su escritura ni sus conceptos como metáforas, sino que deben ser comprendidos de manera literal - esta insistencia se hace muy presente en Deleuze y Guattari en su estudio sobre la escritura de Kafka (1975), que es el caso más privilegiado por Zourabichvili. Sin embargo, como también lo señala Zourabichvili, esta literalidad de los conceptos y de las frases de Deleuze y de Deleuze y Guattari, no implica su reducción a un sentido propio $(2007$, p. 6). Pues el sentido propio remite a una comprensión preestablecida de lo escrito, mientras que el sentido figurado sigue presuponiendo un sentido propio que haría aceptable lo figurado por semejanza o analogía a un sentido primero. Sentido propio y sentido figurado (metáfora) forman una dualidad del lenguaje ordinario que justamente se busca romper con la literalidad: "La literalidad es un proceso que pasa entre las significaciones tal y como el uso ordinario de la lengua las distribuye" [La littéralité, c'est un processus qui passe entre les significations telle

3 Esta cuestión de la literalidad o de al pie de la letra [À la lettre] será también tratada por Zourabichvili en su Vocabulaire de Deleuze [Vocabulario de Deleuze] (2003, p. 3, 25-26, 30, 32, 89). 
que l'usage ordinaire de la langue les distribue] (p. 8). Como indica también Zourabichvili (p. 7-8), la frase que Deleuze solía utilizar: dans l'air du temps (literalmente en castellano: en el aire del tiempo), no debe ser tomada ni como una frase con una significación común en francés (en castellano un equivalente podría ser por los tiempos que corren) que le daría un sentido propio a pesar de que quizá el origen ya haya sido olvidado, ni tampoco como un juego de semejanza entre el aire y el tiempo (que remitiría quizá a una metáfora con un sentido propio preestablecido), sino como dos términos:

[...] que entran en una relación en la que se transforman mutuamente, es decir se comprenden en su interdependencia: el tiempo está explicado en el aire, que está implicado en el tiempo; el aire figura el tiempo como el tiempo figura el aire, no se sabe quién es quién, y cada uno se transporta en el otro porque es transportado por este. [sont pris dans un rapport où se transforment mutuellement c'est-à-dire se comprennent comme interdépendants : le temps est impliqué dans l'air, qui est impliqué dans le temps ; l'air figure le temps comme le temps figure l'air, on ne sait plus qui est qui, et chacun se transporte sur l'autre parce qu'il est transporté par lui] (p. 8).

La literalidad sería aquí este estado de la escritura en el que establece una relación entre términos que no pasaría por el reparto de lo propio y de lo figurado, que sustituiría, neutralizaría o negaría tal reparto a favor de un intercambio inmediato de intensidades. Lo que se deriva de ello para Zourabichvili, es un "desdoblamiento cristalino" [dédoublement cristallin] (p. 13), es decir, una relación en la que los términos se impregnan mutuamente y se vuelven indiscernibles ${ }^{4}$. De tal suerte que Zourabichvili afirma:

La literalidad es la línea, es decir ahí donde escribir y vivir no son más que uno, no porque uno no haga más que en su vida que escribir, o porque no se sepa vivir más que de escritura o en la escritura, sino porque cuando la escritura traza su línea, ésta no se distingue ya más de la vida.

4 En esta definición del cristal, Zourabichvili retoma sin precisar demasiado, el texto de Deleuze Ce que les enfants disent (1993 2, p.81-88) y deja de lado la descripción más desarrollada de la imagen cristal cinematográfica en La imagen-tiempo (DELEUZE, 1985, p. 92-128). Es cierto por otra parte que Zourabichvili mismo reconoce que la falta de análisis de los conceptos de cine es la principal laguna de su Vocabulaire de Deleuze (2003, p. 6). 
[La littéralité c'est la ligne, c'est-à-dire là où écrire et vivre ne sont plus qu'un, non pas parce qu'on ne fait dans sa vie qu'écrire, ou parce qu'on ne sait vivre que d'écriture ou dans l'écriture, mais parce que quand l'écriture trace sa ligne, elle ne se distingue plus de la vie]. (p. 13).

Pero ¿No es este tomar al pie de la letra la indistinción entre escritura y vida el peligro mismo, no ya sólo en Deleuze, sino en la escritura misma? Zourabichvili supone que si se recusa absolutamente tanto el sentido propio como la metáfora, el texto alcanza una suerte de beatitud: la vida. Esta beatitud está presente en el último texto escrito por Deleuze: La inmanencia: una vida (1995):

Una vida es la inmanencia de la inmanencia, la inmanencia absoluta: es potencia, beatitud completas. La vida del individuo ha cedido su lugar a una vida impersonal, y a pesar de ello singular, que extrae un acontecimiento puro liberado de los accidentes de la vida interior y exterior, es decir, liberado de la subjetividad y de la objetividad de lo que sucede "Homo tantum" del cual todo el mundo se compadece y que alcanza una suerte de beatitud (360-361).

Para expresar la beatitud de la vida, Deleuze recurre en este texto a ficcionalizar, a fabular, la inmanencia partir del moribundo de Our Mutual Friend de Dickens (1895), mientras que Zourabichvili fabula la beatitud de la vida desde la escritura de Deleuze. Lo que en el primero tiene un carácter que se podría caracterizar como ontológico (un individuo deja de serlo para pasar a ser una singularidad), en el segundo se convierte en el delirio ontológico de la escritura de Deleuze. El juego de intensidades entre términos o en las frases no garantiza una afirmación de la vida en la escritura ni por la escritura. El reverso de la beatitud en la escritura liberada de la metáfora y del sentido propio - si bien es cierto que Zourabichvili no usa el término beatitud, sí lo supone - es la catástrofe: ¿No es cierto que los grandes fanáticos del Libro son precisamente aquellos que toman lo escrito como literal, es decir, como una escritura sin metáfora ni sentido propio? ¿No son acaso estos mismos fanáticos para los que la sintaxis de la escritura es la sintaxis de la vida misma, a la que además hay que ser fiel en contra de los impíos? Es cierto que la beatitud expresada por Deleuze y la 
beatitud inmanente de la lectura de Zourabichvili de la escritura del maestro no son lo mismo que la beatitud que encuentran los fanáticos de las religiones del Libro. Deleuze escribió: "La sintaxis es el conjunto de desvíos necesarios creados en cada ocasión para revelar la vida en las cosas" [la syntaxe est l'ensemble des détours nécessaires chaque fois crées pour révéler la vie dans les choses] (1993 3, p. 12). Esto concierne para Deleuze una cierta literatura, justamente la de aquellos pocos que para él no se preocupan por ser escritores y que conforman parte de su Panteón personal: Kafka, Le Clézio, los dos Lawrence, Melville, Artaud. Lo que no tiene nada que ver ya no digamos con una lectura pérfida y literal de la sintaxis en el Corán por ejemplo, sino con el resto de la literatura. Pero con la literalidad de Zourabichvili no hay manera de distinguir las dos empresas escriturales: una que revela la vida en las cosas y otra en la que la sintaxis ordena la muerte del otro en aras de la vida auténtica.

\section{Sabattai Zevi, precursor de François Zourabichvili}

Acaso con la pretensión de proclamar una beatitud en la escritura de Deleuze, Zourabichvili esbozó la eventualidad de pensar una locura filosófica de Deleuze, como Derrida abrió el paso a pensar la locura de la razón en Kant. Ambas locuras tienen que ver con la muerte: la de Kant, como señala Derrida, con una lógica del sacrificio (2015, p. 326-327); la de Deleuze, a pesar de Deleuze mismo, y quizá descubierta por Zourabichvili, con el suicidio. No se trata ahora de cuestionar la naturaleza del suicidio de Deleuze. Aunque es cierto que si pensamos las condiciones de su desaparición, podemos intuir que se trató de un suicidio filosófico, en la medida que podemos pensar que se trató de un acto espinosista: una vida condenada a las pasiones tristes de un dolor corporal insoportable no tiene caso ser continuada, hubo que adelantar el proceso de la muerte, que para Deleuze, como para Spinoza, siempre viene de afuera. Pero aquí intuimos otro tipo de suicidio literalmente filosófico al que sin duda no se adscribió el propio Deleuze y del que quizá Zourabichvili fue víctima. En el texto sobre Bartleby, Deleuze 
observa que "Es un texto violentamente cómico, y lo cómico es siempre literal" [C'est un texte violemment comique, et le comique est toujours littéral] (1993 1, p. 89). A lo que había que agregar que la vida, la muerte y el suicidio también siempre lo son, aun en la frase "muerto en vida", aunque acaso no son literales en la expresión que Zourabichvili tiene del término. Y quizá un suicidio filosófico habría que tomarlo siempre literalmente. Al insistir en la cuestión de la literalidad, aunque ciertamente algunos pasajes de Deleuze y de Deleuze y Guattari se podrían prestar a esta lectura, lo que Zourabichvili descubre es una esquizofrenia en la sintaxis de Deleuze, que lo lleva fatalmente a confundir la literalidad con la inmanencia. Pues es a partir de la sintaxis que Zourabichvili entiende la cuestión de la escritura de Deleuze como literalidad: así, las palabras y las frases dejan de tener un sentido propio o metafórico y se convierten en signos a-significantes, como lo habrían querido Deleuze y Guattari. Es en este aspecto que el caso de la justicia en Kafka, que Zourabichvili trae a colación se vuelve ejemplar:

Resulta que, a partir del momento en el que la justicia se escribe, que es puesta en signos, semiotizada como agenciamiento de deseo, aquel que escribe ya no se encuentra en situación de describirla o de significarla, sino que recibe de latigazo pleno todas las circunstancias, incluidas las palabras, es decir las palabras entendidas en su intensidad más que en su poder referencial. [C'est que, à partir du moment où la justice est écrite, mise en signes, sémiotisée comme agencement de désir, celui qui écrit n'est plus en situation de la décrire ou de la signifier mais il en reçoit de plein fouet toutes les circonstances, à même les mots, c'est-àdire les mots traités [...] dans leur intensité plutôt que dans leur pouvoir de référenciation] (p. 9).

Efectivamente, si la sintaxis de una escritura compone por si sola el agenciamiento de deseo (neutralizando su nivel referencial), lo único que se puede esperar es recibir violentamente todas las circunstancias, no solamente en Kafka, sino de todo escritor que pretenda la literalidad propuesta como grille de lecture de Zourabichvili para Deleuze. Pues la literalidad en Zorabichvili es un recurso sintáctico que en lugar de salir del lenguaje, lo afirma. Al referirse a la frase "ha soportado de menos en menos las palabras" [a supporté de moins en moins les mots] de 
Deleuze sobre Beckett (1992, p. 103), Zourabichvili no deja dudas de que busca un uso puro del lenguaje: "es aquí que el lenguaje llevado a su límite hace ver, y desprende una visión que no existe fuera del lenguaje y que no es el doble imaginativo que se le otorga ordinariamente a las palabras" [c'est là que le langage ainsi porté à sa limite fait voir, dégage une vision qui n'existe pas hors du langage, et qui n'est pas le double imaginatif accolé ordinairement aux mots] (p.13). Que la relación entre términos sea ya cristalina y "en el límite del lenguaje" en lugar de metafórica o de sentido propio sólo agrava el problema, pues mientras no haya un afuera - y no lo hay en Zourabichvili - la sintaxis deviene un lenguaje puro, una Ley del Padre que pasa cristalinamente de un término a otro. Es bien conocida la posición que Deleuze y Guattari tienen del lenguaje: "el lenguaje no está hecho incluso para ser creído, sino para obedecer y hacer obedecer. [...] El lenguaje no es la vida, da órdenes a la vida; la vida no habla, ella escucha y espera. En toda orden [mot d'ordre], incluso de un padre a su hijo, hay una pequeña sentencia de muerte - un Veredicto, decía Kafka" (1980, p. 96). El límite cristalino de la relación entre términos (sintaxis), es decir de la indistinción e interferencia asignificante, no puede ser otro que la indistinción literal entre vida y muerte, entre empresa de vida y empresa suicida. Se puede objetar que se es demasiado severo en este punto. Pero tiene que ser así, porque para distinguir plenamente ambas empresas a partir de su sintaxis tendríamos que establecer criterios de interpretación de los textos, pero esto es justamente lo que rechazan Deleuze y Guattari por un lado y Zourabichvili por el otro, porque ello implica suponer textos que se diferencian por su sentido propio y luego implica también la adjudicación de lecturas erróneas de cada texto. Aun si suponemos que dos textos no tienen sentido propio, por ejemplo Seven Pilars of Wisdom de T. E. Lawrence (1922) y El Génesis bíblico ¿Cómo saber si nos encontramos frente a la beatitud en un caso y frente a una moral del sacrificio en otro? ¿Dónde encontrar la diferencia de su rechazo a la interpretación entre Deleuze y Guattari por un lado, y Zourabichvili por el otro?

Resulta curioso que sea precisamente con un recurso a Kafka que Deleuze y Guattari busquen liquidar al lenguaje, algo que de 
ninguna manera hizo Zourabichvili con su lectura del Kafka de Deleuze y Guattari. Y no lo pudo hacer porque buscó entender la escritura de Deleuze y de Deleuze y Guattari, como una cuestión que comprende al vértigo (el juego de intensidades en la escritura) como una causa interna a las palabras y las frases, es decir sintáctica, y en esta medida lingüística, puramente langagière como les gustaba decir a Deleuze y Guattari. La literalidad de Zourabichvili acaba siendo una puesta en escena en la que la Ley del Padre implicada en la escritura se confunde y se vuelve indistinguible de la beatitud, las fuerzas vitales y de fuga que a pesar de todo rondan en el vértigo. Pero el vértigo mismo no es sino un efecto de la relación de las palabras, de la escritura, del lenguaje, con su afuera, que no es de ninguna manera lingüístico, ni sintáctico, sino, aquí sí, literalmente cinematográfico: lo que faltó a la literalidad de Zourabichvili es el fuera de campo de la escritura, la corriente de aire fresco extratextual que transforma, que desterritorializa, que destituye las palabras, en favor de aquello que no habla: la vida, el gesto.

Borges apuntó en Kafka y sus precursores (1952) que "cada escritor crea a sus precursores" 8p. 712). Es decir, cada escritor crea afinidades a posteriori con autores anteriores y afecta la manera en que los leemos. Finalmente, nadie escoge a sus ascendientes, incluso en la escritura: el precursor de François Zourabichvili no sería tanto Deleuze, sino el falso Mesías Sabattai Zevi, quien en el Siglo XVII, después de haberse autoproclamado como el Mesías de Israel, y haber propiciado con ello una gran expectativa redención entre gran parte de los judíos del Imperio Otomano, se convirtió al Islam y abandonó a sus fieles (los Dönmeh), quienes a su vez, para evitar comprender este acto inusitado como una vulgar traición, buscaron entenderla como un mandato cabalístico de fe que les indicaba practicar un criptojudaísmo en el seno del Islam. Para un creyente en la magia no hay nada más obtuso que la nítida realidad: la traición de Zevi fue diáfana, pues ello demostraba (si se estaba dispuesto a conectar las pretensiones mesiánicas de Zevi con la realidad exterior) que era un humano corriente. Pero esto no podía ser comprendido así por quienes habían empeñado su fe en creer que un Mesías encarnado no podía traicionar a su pueblo. Para los seguidores de Zevi era imposible concluir esta conexión literalmente cómica 
con el afuera (Zevi como impostor), pero para ello precisaron crear una interpretación cabalística que anulara el hecho exterior (la conversión al Islam de Zevi no habría sido una traición, sino una especie de mandato para practicar una doctrina esotérica judía en el seno de un Islam exotérico).

Habría algo de cabalístico y mágico en la literalidad de Zourabichvili. Para parafrasear el célebre pasaje de Pierre Menard, autor de El Quijote, también de Borges (1939) con una pequeña modificación: la beatitud de la escritura de Deleuze en Zourabichvili y la beatitud de la vida en Deleuze son casi textualmente idénticas, pero la segunda es casi infinitamente más rica ${ }^{5}$. Lo es porque la primera supone un acto mágico interior a las palabras, que pretende que una frase común como dans l'air du temps proferida en el texto cuasi-sacro tenga otra fuerza que la misma frase proferida en la cotidianidad - Aquí la potestad del Padre filosófico que fue Deleuze para Zourabichvili no puede ser más nítida -. Mientras que la segunda, más humilde, requiere por parte del lector una actitud activa que conecte simple y técnicamente las palabras con la fuerza más exterior al texto. Si bien para Zourabichvili esta fuerza exterior pudiera ser el "doble imaginativo que se le otorga ordinariamente a las palabras", este doble en realidad es el afuera mismo, lo más exterior que permite que haya cosas y su repetición y referencia en las palabras: si se anula esta potencia del doble, se anula la repetición y queda el puro lenguaje. La primera beatitud recurre subrepticiamente al acto mágico de un Padre en la sintaxis, pero se trata de un efecto local y forzado, de una brujería averiada, que como toda brujería fallida, su único peligro, aunque mortal, es el ser tomada en serio. La segunda es sobria y sin magia, aunque transforma las palabras en mero engranaje del Cosmos. Zourabichvili rinde culto a un Mesías filosófico de apellido Deleuze, pero ante el embate del afuera se ve obligado a recurrir al hechizo ineficaz de una lectura delirante. Más filosóficamente incrédulo y más filosóficamente impío (más filosóficamente sano también),

\footnotetext{
5 "El texto de Cervantes y el de Menard son verbalmente idénticos, pero el segundo es casi infinitamente más rico" (BORGES, 1939, p. 14). Esta frase fue utilizada por Deleuze en el prefacio de Différence et répétition [Diferencia y repetición] (1968) para indicar que "Entonces la repetición más exacta, la más estricta tiene por correlato el máximo de diferencia [Alors la répétition la plus exacte, la plus stricte a pour corrélat le maximum de différence]. (p. 5).
}

Rev. Filos., Aurora, Curitiba, v. 29, n. 46, p. 231-256, jan./abr. 2017 
Deleuze se limita a considerar y a crear efectos de montaje en la filosofía misma ${ }^{6}$.

\section{A manera de conclusión: la serenidad de Deleuze}

Es cierto que la idea cinematográfica de la escritura de Nietzsche por parte de Deleuze es anterior a los textos que hace referencia Zourabichvili, y que estos últimos pueden ser comprendidos como una especie de corrección o de profundización a lo que Deleuze pensó respecto a la escritura de Nietzsche o a la suya propia. Pero en su primitivismo y sencillez es también posible tomarla como un programa de lo que Deleuze escribirá incluso mucho después. La literalidad de Zourabichvili no sólo es lingüística, sino ontológica y metafísica,

6 Más que errónea u obtusa, habría que calificar la propuesta de Zourabichvili como delirante. Como en muchos lugares lo han demostrado Deleuze y Guattari, habría una riqueza y una productividad en el delirio (pero también un peligro del que no siempre se sale indemne). La anécdota de Zevi es también testimonio de ello, como lo sostiene Gershom Scholem en Mesianismo y nihilismo (2011), sobre todo en el apartado "La redención a través del pecado" (pp. 65-150), en el que analiza como los seguidores de Zevi, lejos de rechazarlo por impostor y apóstata, buscaron comprender su acto como el signo divino de una nueva era y un nuevo mandato, en el que el auténtico cumplimiento de la Ley, se da transgrediéndola. Se trata de una fe paradójica que quizá pudiera pensarse como un complemento al texto ya citado de Deleuze sobre Sacher-Masoch (1967). Pero más allá de esta incidencia, habría que considerar si la lectura de la práctica deleuziana de la escritura puede ser emprendida hoy sin enfrentarse al dilema de optar por la lectura para-cabalistica de Zourabichvili o por la montajista del joven Deleuze. Por supuesto, la cuestión no puede zanjarse definitivamente. Sin embargo, lo que aquí se expone intuye que el propio Deleuze, a pesar de su interés por los efectos locales del simulacro (DELEUZE, 1969, p. 292-324) y la brujería (DELEUZE Y GUATTARI, 1980, p. 309), no suscribió su propia práctica como un efecto puramente escritural y de lenguaje, lo que dejaría de lado toda surenchère (sobrepuja) por comprender a Deleuze literalmente y como un autor que estaría, ya por designio propio, ya bien por la lectura de sus discípulos, más allá toda implicación metafórica. Es por eso que aquí se insiste en que habría que considerar a Zourabichvili menos como un sucesor de Deleuze y de Spinoza, que como un "comentador de textos", pero sobre todo como un continuador filosófico de los seguidores de Zevi. Es posible que al llevar la puja de la literalidad al límite, Zourabichvili no sólo no sea deleuziano, sino que devenga mesiánico en el sentido de los seguidores de Zevi. De acuerdo a lo anterior, Zourabichvili sería un falsario como los que anuncia el propio Deleuze (1985, p. 165-202). Es cierto que para Deleuze, el falsario no es un personaje puramente negativo, aunque el tipo de falsario de Zourabichvili sería bien particular: aquél que al pretender descubrir la verdad de la palabra mesiánica, se postula subrepticia y narcisísticamente como el sucesor del Mesías o incluso como el Mesías mismo. En efecto, un Mesías no puede equivocarse ni fallar, por ello hay que entender su escritura y sus actos literalmente. Así el suicidio de un joven filósofo no tendría que ser visto como un signo extratextual de debilidad y falla humana que nos cause tristeza, sino como una manifestación literal de beatitud absoluta que encuentra en tal acto el límite heroico de una vida y de una lectura, lo que no parece ser justo ni con Deleuze ni con el propio malogrado Zourabichvili. 
con un Padre terrible que vuelve inconfundible la escritura, la filosofía y la vida. Mientras que la extratextualidad del joven Deleuze es una simple indicación técnica: "si se quiere saber lo que quiero decir, encuéntrese la fuerza que da un sentido, o un nuevo sentido, a lo que digo. Conéctese el texto a esta fuerza"; hay que hacer "pasar algo, una corriente de energía". No es una indicación de erudito en materia alguna ni de comentador de textos, sino una indicación que pudiera ser la de un mecánico, la de un tramoyista o electricista: "conéctese el texto a esta fuerza". Es casi una instrucción de uso de un aparato o de un equipo doméstico. En suma, es una indicación de un montajista que sólo busca la fuerza azarosa que da un sentido a un texto en determinado momento. Por ello mismo, la fuerza que surge de este encuentro entre dos realidades no es ni ontológica ni metafísica, ni sintáctica. Por eso no hay un Padre ni una Ley que temer. El afuera es el riesgo mismo que es la vida. El vértigo viene de la conexión con el afuera, es decir, del azar, que es lo que convierte a la escritura, más allá de la sintaxis y de la literalidad, en potencia de lo falso ${ }^{7}$.

La revelación de la vida en las cosas que implica una sintaxis inmanente propuesta por Deleuze sólo puede ser llevada a cabo cuando la escritura es comprendida como elemento de montaje. Es por el montaje extratextual y extraescritural y no por la escritura misma que un aire frenético viene a darle un sentido nuevo a las palabras y que la sintaxis cobra vida falseando el sentido propio y la literalidad. A pesar de Deleuze y Guattari, no es por la insistencia explícita en que lo escrito no es metáfora, que nos libramos de la metáfora ni de la opresión del lenguaje, sino por la conexión implícita e inmanente del texto y la sintaxis con el afuera, la vida, el vértigo, el Cosmos, que vuelve inútil la cuestión de la metáfora, así como las vanas cuanto rebuscadas justificaciones de aquellos que insisten en que la correcta lectura de los textos del maestro implica deshacerse de toda metáfora. Una corrección sigue siendo una corrección, aunque se haga en nombre de Deleuze, como lo hace Zourabichvili: “Deleuze y Guattari leen bien a Kafka y de una

7 Sobre las potencias de lo falso del arte en Nietzsche según Deleuze véase (DELEUZE, 1962, p. 166-117); y en el cine (1985, p. 165-202). 
cierta manera pretenden decir que es, de acuerdo a ellos, que los textos de Kafka [sic], y por consecuencia como deben y como no deben ser leídos" [Deleuze et Guattari lisent bien Kafka d'une certaine façon, et prétendent dire ce que c'est, d'après eux, que les textes de Kafka, et par conséquent comment il faut les lire et ne pas les lire] (2007, p. 2). Del afuera vendrá también algún día la muerte, que no deja de implicar temor, pero ya no se trata del miedo del niño libresco que asimila literalmente una vida justa con una empresa suicida. Rosset (1972) escribió alguna vez de la sequedad de Deleuze. Es decir de la paradójica fuerza de la falta de entusiasmo en su escritura. Si la locura de Deleuze se encuentra en la sintaxis, tomada como causa sui, y su sequedad en su estoicismo escritural, su política superior, es decir, su serenidad o sobriedad, se encuentra en su extratextualidad cinematográfica.

La extratextualidad implica también el enfrentamiento con la muerte y con un pensamiento que ha cedido a las prerrogativas de la tristezas cotidianas y de la tristeza máxima que es la muerte. Dicho en términos políticos, el enemigo principal de Deleuze - y esto lo vio bien Foucault - es el fascismo, entendido como política de la muerte - todo aquel que dice jviva la muerte! Es un fascista para Deleuze -. Hoy día, ello implica la ardua construcción de una escritura estético-política que al conectarse con su afuera sea capaz de vencer a la muerte, o mejor dicho, al sentido que implica la muerte, aun si finalmente ésta viene a cobrar sus derechos. Se tratará de una escritura futura que con rigor y un cierto candor entablará un montaje infinito: aquel en que las conexiones entre texto, plano, y fuera de campo conjurarán la política de la muerte con la leve música y el fino tacto de una ternura a la vez singular y cósmica.

\section{Referencias}

AGAMBEN, G. El Reino y la Gloria. Valencia: Pre-Textos, 2008.

BENJAMIN, W. Hacia la crítica de la violencia. In: Obras, Libro II / v. 1. Madrid: Abada, 2007. p. 183-207. 
BORGES, J. L. Pierre Menard, autor del Quijote. Sur, No. 56, p. 7-16, Año IX, Mayo, 1939.

BORGES, J. L. La velocidad es una conquista de nuestra época ¿Cree usted que es útil? [Respuesta a encuesta]. Revista El Hogar, 7 de septiembre de 1945. In: Borges en El Hogar. 1935-1958. Buenos Aires: Emecé, 2000. p. 166.

BORGES, J. L. Kafka y sus precursores. [Otras inquisiciones, 1952]. In: Obras completas. Buenos Aires: Emecé, 1974 [Primera edición]. p. 710-712.

DELEUZE, G. Nietzsche et la philosophie [Nietzsche y la filosofía]. París: Presses Universitaires de France, 1962.

DELEUZE, G. Présentation de Sacher-Masoch, Le froid et le cruel [Presentación de Sacher-Masoch. Lo frío y lo cruel]. París: Minuit, 1967.

DELEUZE, G. Différence et répétition [Diferencia y repetición]. París: Presses Universitaires de France, 1968.

DELEUZE, G. Simulacre et philosophie Antique. In: Logique du sens [Lógica del sentido]. París: Minuit, 1969.

DELEUZE, G. Pensée nomade [Pensamiento nómada]. Nietzsche aujourd'hui ? Tome I. Intensités. París: UGE 10/18, 1973. p. 159-190. In: L'île déserte. Textes et entretiens. 1953-1974. París: Minuit, 2002. p. 351-364.

DELEUZE, G. Table ronde sur Proust [Con Roland Barthes, Gerard Genette, Jean Ricardou, Jean-Pierre Richard]. Cahiers Marcel Proust. Nueva serie n. 7. París: Gallimard, 1975. p. 87-116. In: Deux Régimes de fous. 1975-1995. París: Minuit, 2003. p. 29-55.

DELEUZE, G. Cinéma 2. L'Image-temps [La Imagen-tiempo. Estudios sobre cine 2]. París: Minuit, 1985.

DELEUZE, G. Le pli, Leibniz et le Baroque [El pliegue. Leibniz y el Barroco]. París: Minuit, 1987.

DELEUZE. L'Épuisé: In: BECKETT, S. Quad et autres pièces pour la télévision. Suivi de L'Épuisé par Gilles Deleuze. París: Minuit, 1992. p. 55-106. 
DELEUZE, G. Bartleby, ou la formule [Bartleby o la fórmula]. In: Critique et clinique [Crítica y clínica]. París: Minuit, 1993. p. 89-114 [1993 1].

DELEUZE, G. Ce que les enfants disent. In: Critique et clinique [Crítica y clínica]. París: Minuit, 1993. p. 81-88 [1993 2].

DELEUZE, G. La littérature et la vie. In: Critique et clinique [Crítica y clínica]. París: Minuit, 1993. p. 11-17 [1993 3].

DELEUZE, G. L'Immanence : une vie [La inmanencia: una vida]. Philosophie n. 47 p. 3-7, septiembre 1995. In: Deux Régimes de fous. 1975-1995. París: Minuit, 2003. p. 359-363.

DELEUZE, G.; GUATTARI, F. L'Anti-CEdipe. Capitalisme et Schizophrénie 1. [El Anti-Edipo. Capitalismo y esquizofrenia 1]. París: Minuit, 1973.

DELEUZE, G.; GUATTARI, F. Kafka, Pour une littérature mineure. [Kafka. Por una literatura menor]. París: Minuit, 1975.

DELEUZE, G.; GUATTARI, F. Mille Plateaux. Capitalisme et Schizophrénie 2 [Mil Mesetas. Capitalismo y esquizofrenia 2]. París: Minuit, 1980.

DELEUZE, G.; GUATTARI, F. Qu'est-ce que la philosophie? [¿Qué es la filosofía?]. París: Minuit, 1991.

DERRIDA, J. De la grammatologie. París: Minuit, 1967.

DERRIDA, J. Séminaire La peine de mort (2000-2001) vol. 2. París: Galilée, 2015.

DICKENS. C. Our Mutual Friend. Londres: Chapman \& Hall, 1895.

DUMÉZIL, G. Mitra-Varuna. Essai sur deux représentations indo-européennes de la souveraineté. París: Leroux, Presses Universitaires de France, 1940.

FOUCAULT, M. Theatrum Philosophicum. Critique n. 282, p. 885-908, noviembre 1970, In: Dits et Écrits, Tomo II 1970-1975. París: Gallimard N.R.F., 1994. p. 75-99.

KANT, I. La metafísica de las costumbres. Madrid: Tecnos, 2008. 
LAWRENCE, T.E. Seven Pilars of Wisdom. Oxford: Edición privada, 1922.

LE CLÉZIO, J. M. G. Haï. Ginebra: Albert Skira, 1971.

ROSSET, C. Sécheresse de Deleuze. L'Arc, n. 49. Deleuze, p. 89-93, Segundo trimestre 1972.

SCHOLEM, G. Mesianismo y nihilismo. Buenos Aires: Prometeo Libros, 2011.

ZOURABICHVILI, F. Le vocabulaire de Deleuze. París: Ellipses, 2003.

ZOURABICHVILI, F. La question de la littéralité. Klesis Revue Philosophique, n. 5.1. Autour de François Zourabichvili [En línea], p. 1-13, abril 2007. Disponible en: <http://www.revue-klesis.org/pdf/F-Zourabichvili.pdf>. Accedido el 24 ago. 2016.

Recibido: $15 / 12 / 2016$

Recebido: 15/12/2016

Aprobado: 07/02/2017

Aprovado: 07/02/2017 